\title{
Total Productive Maintenance for the Sewing Process in Footwear
}

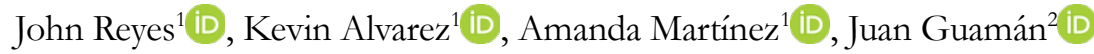 \\ ${ }^{1}$ Universidad Técnica de Ambato (Ecuador) \\ ${ }^{2}$ Universidad Técnica del Norte (Ecuador) \\ johnpreyes@uta.edu.ec, kealvarez0229@uta.edu.ec, amandamartinesyacelga@gmail.com,jfguaman@utn.edu.ec
}

Received: May 2018

Accepted: September 2018

\section{Abstract:}

Purpose: This research proposes an implementation model of Total Productive Maintenance (TPM) based on the analysis of criticality of machines in the sewing process in the Ecuadorian footwear industry and the identification of unproductive times caused by labor failures.

Design/methodology/approach: The project uses field research, presents a quantitative approach, the data collection is done in a horizon of 8 months in which the information is condensed in data tables and takes as a case study one of the most successful companies in the Ecuadorian footwear industry for its initiative to innovate their processes and research new technologies that help increase their efficiency.

Findings: The results allow to demonstrate the successful application of the proposed model in the industrial sector of footwear with an increase of average production standards of $5 \%$ and a reduction in the number of human errors of $72.2 \%$.

Practical implications: The model allows to execute several activities in four phases: preparatory, introduction, implementation and consolidation in order to develop TPM in sewing process.

Originality/value: The paper describes a case study in a major shoe company with the aim of reducing the times for unscheduled stoppages and the number of failures.

Keywords: TMP, footwear, shoe company, industry

\section{To cite this article:}

Reyes, J., Alvarez, K., Martínez, A., \& Guamán, J. (2018). Total productive maintenance for the sewing process in footwear. Journal of Industrial Engineering and Management, 11(4), 814-822. https://doi.org/10.3926/jiem.2644

\section{Introduction}

At the global level, the application of Lean Manufacturing strategies has become one of the most applied methodologies in order to reduce costs and improve the continuous flow, being aware that in order to advance, it is necessary to introduce changes in production processes. Organizations have implemented continuous improvement methodologies in their processes to guarantee their sustainability in highly changing markets (Marulanda \& González, 2017). 
Shoe production is one of the most important industries in the city of Ambato in Ecuador. Thus, due to the growing demands of the current market and the accelerated change in the economy, it is essential to look for strategies not only at a commercial level, but also at a productive level that directly affects the optimization of resources.

In Ecuador, lean manufacturing strategies have been little studied and it is common to find in the production lines an endless number of non-value-added activities that increase the delivery times of Ecuadorian products (Álvarez, Aldas \& Reyes, 2017). The limited application of Total Productive Maintenance (TPM) and other Lean strategies in the Ecuadorian footwear industry directly influences the progress of organizations by not improving their production processes and increasing their costs due to not optimizing their production times and with high levels of sub-assemblies and defective finished products.

TPM proposes a prescriptive implementation methodology in which the steps that companies must follow to implement the process and obtain the expected benefits are detailed (Villegas \& Velez, 2014). To achieve a dynamic and profitable growth in the long term, this strategy is based on the analysis of parameters known as "Availability", "Performance" and "Quality", which include from the contribution generated by each machine of the system up to the quality of the finished product and the efficiency of the operators in the working day (Matos, 2012) the same leading to optimal levels for productive plant efficiency, with the multiplication of these three parameters the Overall Equipment Effectiveness (OEE) measure is obtained.

TPM is a strategy composed of a series of organized activities that once implemented help improve the competitiveness of an industrial or service organization. The total productive maintenance is a widely used strategy in the productive areas, which is aimed at increasing the availability of machinery and production equipment, as well as the economic benefits of the companies (García, Romero \& Noriega, 2012).

TPM is currently one of the most complete strategies to achieve efficiency and competitiveness, which allows to reach high quality standards, through compliance with planned stoppages, reduction of unproductive times and consequently in optimal costs. TPM must be supported by base elements such as: senior management commitment, strategic plan, focus on human resources, process approach and focus on the information system (Marín \& Martínez, 2013). The benefits of the application of the TPM are based on the predisposition and awareness of adopting changes in the workers, motivated by an integral philosophy and directed by senior management, transforming itself into a strategic and functional objective.

The implementation of a TPM model implies keys that allow the success of its application, based on action plans, training at all levels, monitoring of indicators; considering characteristics of organizations, as well as the ability to face and react to the activity of the productive process (Villegas \& Velez, 2014).

The objective of this research is to propose a model of implementation of TPM for the footwear industry that directs in a structured way the activities that must be carried out to achieve the reduction of unproductive times in the machines and thus improve the production standards. The analysis is carried out in an important Ecuadorian footwear company in which the results are evaluated, referred to the increase of standards and decrease of human errors.

The paper begins by presenting a brief synopsis of the principles applied in this study, followed by background on the work done in this research. The selection of the root cause and the analysis of unscheduled stoppages, type of machine failures and maintenance costs are made. Finally, the results of the implementation of the TPM model are analyzed.

\section{Methodology}

The project uses field research, presents a quantitative approach, the data collection is done in a horizon of 8 months in which the information is condensed in data tables and takes as a case study one of the most successful companies in the Ecuadorian footwear industry for its initiative to innovate their processes and research new technologies that help increase their efficiency. Customers demand shorter delivery times representing a major challenge in the search for tools to achieve flexible production systems (Álvarez, Aldas \& Reyes, 2017). In this context, Lean Manufacturing is a methodology that achieves this goal by eliminating waste during production, with 
specific strategies that are implemented as appropriate. These strategies include standard work, single minute exchange of dies (SMED), total productivity maintenance (TPM), and mistake proofing (Jidoka) (Pearce \& Pons, 2013).

The production process in the footwear begins with the modeling where the designs are developed, at this point it is chosen if the footwear will be sewn in manual or automatic machine taking into account that most follow the same pattern in their production processes (Reyes, Aldas, Salazar, Armendariz, Álvarez, Nuñez et al., 2017). Already in the productive process the pieces are cut and sent to the sewing process. The next process is the assembly of the shoes where the cut is mounted to the last and adhere to the sole. The last process is the finishes where the laces and insole are placed for final packaging and delivery to finished product warehouses.

The study focuses on the TPM implementation for the reduction of unscheduled production stoppages and unproductive times during the workday. The implementation model of Figure 1 is proposed with 10 consecutive steps from the launch of the TPM to the verification of results. The investigation is executed in the sewing process that counts mainly with manual machines. However, thanks to advances in technology Ecuadorian footwear industry can be supported with automatic sewing machines that provide greater flexibility in models that can be developed. The application of these machines implies that the workers are specialized and maintenance becomes a critical activity since a production stoppage represents high costs and if the damage is greater, the development of the footwear must be rethought to use manual machines.

TPM is a system designed to eliminate waste from machines such as downtime, unscheduled shutdowns, operation at lower speeds and defective products. It is a culture where operators develop a sense of ownership for their machines and become allies of maintenance staff to ensure that machines operate properly every day. Lean contributes to create an environment in which people share similar values and behaviors (Soliman, Saurin \& Anzanello, 2018). The operational thinking of the TPM is: "My machine, my responsibility, I receive well, I deliver well".

The first step required for the TPM implementation is to carry out a training campaign and promote an adequate environment for the use of this tool, the campaign must be focused on the understanding of the TPM and recognition of the benefits it brings. Next, all of the company's employees must be informed of the management's decision to implement the TPM and which will be the goals to be achieved. It should be taken into account to incorporate into the strategic planning of the company to make explicit decisions for the long term (Hernández, Escobar, Larios \& Noriega, 2015).

It is necessary to draw up a plan of activities to be executed with dates of compliance and responsible bearing in mind that the following steps of the implementation model of Figure 1 are mandatory execution.

One of the most important meetings should be with the team is called Kickoff. The kick-off should be designed to cultivate an atmosphere that raises morale and inspires dedication. In Japan, it is often a companywide meeting to which client companies, affiliates and subcontractors are invited. At the meeting, top management reconfirm their commitment to implementing TPM and report on the plans developed and the work accomplished during the preparation phase (Suzuki, 1994).

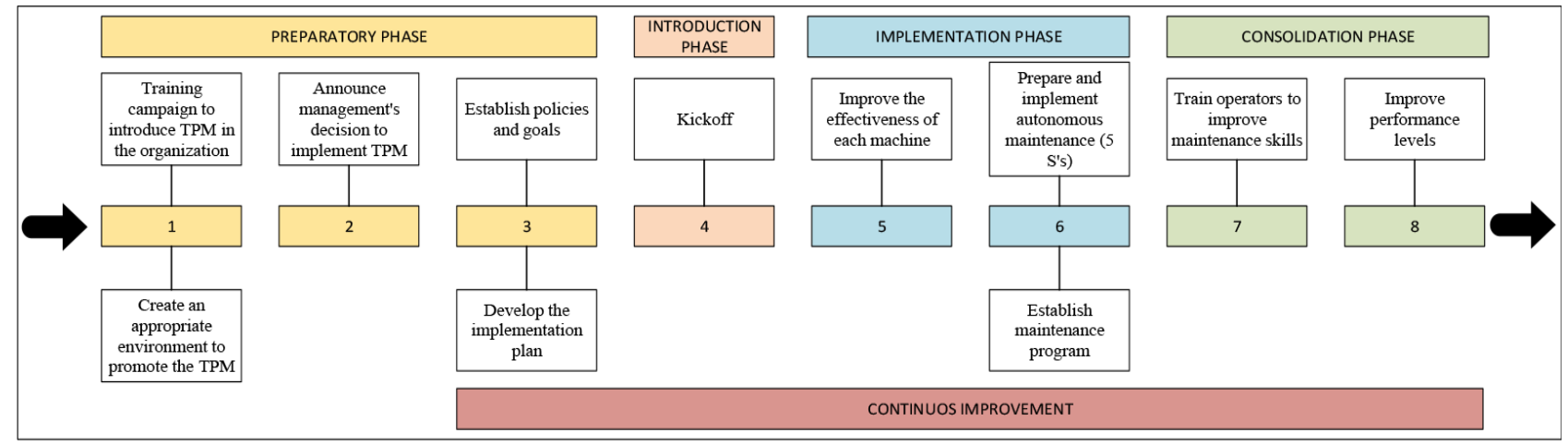

Figure 1. Implementation Model 
In the next five steps the improvements are implemented once the critical machines are identified, which in the case of the project are the automatic machines.

The criticality analysis of machines is done through the evaluation of 7 aspects and their level of risk. The aspects evaluated are: industrial safety (IS), environment (E), quality and productivity (Q), time of operation (OT), production $(\mathrm{P})$, time between failures (TMBF), time to repair and maintenance costs (TMTR).

For each aspect, the level of risk that the machine presents must be identified. There are three risk categories: high $(\mathrm{H})$, medium $(\mathrm{M})$ and low $(\mathrm{L})$. Table 1 shows an example for the analysis between a manual and automatic sewing machine.

\begin{tabular}{|c|c|c|c|c|}
\hline Machine & Aspect & Risk & Risk Description & Criticity \\
\hline \multirow{7}{*}{ Manual Machine 1} & IS & $\mathrm{M}$ & Minor damage to staff health & \multirow{7}{*}{ UNCRITICAL } \\
\hline & $\mathrm{E}$ & $\mathrm{L}$ & Normal emissions within the permitted limits & \\
\hline & Q & M & Variation in quality and production specifications & \\
\hline & OT & M & 2 shifts or normal work hours & \\
\hline & $\mathrm{P}$ & M & Stop part of the process & \\
\hline & TMBF & M & On average once a year & \\
\hline & TMTR & $\mathrm{L}$ & Irrelevant time and repair costs & \\
\hline \multirow{7}{*}{ Automatic Machine 1} & IS & M & Minor damage to staff health & \multirow{7}{*}{ CRITICAL } \\
\hline & $\mathrm{E}$ & $\mathrm{L}$ & Normal emissions within the permitted limits & \\
\hline & Q & $\mathrm{H}$ & Production defects & \\
\hline & OT & $\mathrm{H}$ & 24 hours a day & \\
\hline & $\mathrm{P}$ & $\mathrm{H}$ & Stop the entire process & \\
\hline & TMBF & $\mathrm{H}$ & Less than 6 months & \\
\hline & TMTR & $\mathrm{H}$ & High time and repair costs & \\
\hline
\end{tabular}

Table 1 . Machine criticality analysis

\section{Results}

\subsection{Developing TPM}

Table 2 shows the activities that are developed for the implementation of TPM in each stage during the research. It is considered a grouping with four phases: preparatory that focuses on planning, introduction for the launch of the tool, implementation in which improvements are carried out and consolidation for analysis of results and continuous improvement.

The philosophy and techniques of lean manufacturing are a need in business environment (Pacheco, Carbajal \& Stoll, 2017), in a structured way the application of TPM allows the reduction of failures in critical machinery like automatic machines on sewing process. The activities proposed in Table 1 ensure that the analysis is complete and planned during the execution of the research project. TPM should not be seen only as an initial application strategy, but as a strategy for continuous application, learning and implementation of a culture where the worker is empowered by his machine. 


\begin{tabular}{|c|c|c|c|}
\hline Phase & $\mathbf{N}^{\circ}$ & Stage & Actions \\
\hline \multirow{5}{*}{ Preparatory } & 1 & $\begin{array}{l}\text { Training campaign to introduce } \\
\text { TPM in the organization }\end{array}$ & \multirow{2}{*}{ Disclose TPM in all areas of the company } \\
\hline & 2 & $\begin{array}{l}\text { Create an appropriate environment } \\
\text { to promote the TPM }\end{array}$ & \\
\hline & 3 & $\begin{array}{l}\text { Announce management's decision } \\
\text { to implement TPM }\end{array}$ & Disclose through internal newspapers \\
\hline & 4 & Establish policies and goals & $\begin{array}{l}\text { Establish the scope and responsibilities of TPM operators } \\
\text { Control and handling of pallets } \\
\text { Edition responsibility } \\
\text { Definition of speeds and standards according to model } \\
\text { Measure die-cutting delivery service }\end{array}$ \\
\hline & 5 & Develop the implementation plan & $\begin{array}{l}\text { Structure and define the people for the implementation } \\
\text { committee }\end{array}$ \\
\hline Introduction & 6 & Kickoff & Detailed description of the implementation plan at all levels \\
\hline \multirow{3}{*}{ Implementation } & 7 & $\begin{array}{l}\text { Improve the effectiveness of each } \\
\text { machine }\end{array}$ & $\begin{array}{l}\text { Select the critical machine: manual or automatic } \\
\text { Measure losses: kind of failures on sewing process } \\
\text { Implement OEE measure } \\
\text { Set priorities and plan improvement } \\
\text { Implement improvement activities } \\
\text { Follow up on activities }\end{array}$ \\
\hline & 8 & $\begin{array}{l}\text { Prepare and implement } \\
\text { autonomous maintenance ( } 5 \text { S's) }\end{array}$ & $\begin{array}{l}\text { Initial cleaning } \\
\text { Preventive measures cleaning } \\
\text { Establishment of cleaning and inspection standards } \\
\text { Autonomous inspection }\end{array}$ \\
\hline & 9 & Establish maintenance program & $\begin{array}{l}\text { Preventive Maintenance for Sewing Process } \\
\text { Predictive Maintenance for Sewing Process } \\
\text { Prevention of maintenance }\end{array}$ \\
\hline \multirow{2}{*}{ Consolidation } & 10 & $\begin{array}{l}\text { Train operators to improve } \\
\text { maintenance skills }\end{array}$ & $\begin{array}{l}\text { Train and demonstrate how to work as a TPM operator } \\
\text { according to the defined scope } \\
\text { Security, Quality and Productivity }\end{array}$ \\
\hline & 11 & Improve performance levels & $\begin{array}{l}\text { Redefine production standards } \\
\text { Ensure that downtime is minimized } \\
\text { Check the number of weekly failures }\end{array}$ \\
\hline
\end{tabular}

Table 2. Actions to implement TPM in the Sewing Process

\subsection{Use of Automatic Machines in Sewing Process}

The sewing process has manual and automatic machines for the realization of its activities. In recent years in the Ecuadorian footwear company the need for the use of automatic machines has increased due to the fact that it presents greater advantages in terms of productivity and allows innovation in the designs due to the ease it provides in sewing. However, this type of machines requires qualified people to handle them and the editing times are extensive.

The project performs a cause and effect diagram that allows identifying the root cause by which the TPM application is initiated. About machinery there is lack of training, machinery damage, lack of control and pallets in poor condition. Related to method there is turn-by-turn jobs are not scheduling in automatic machines and lack of continuity in operations. Materials there is delayed die-cutting and late supply of cuts. Finally about workforce there is lack of training, extensive editing times, production failures, dead time to produce and speed manipulation. So in the analysis it is observed that the insufficient management of automatic machines causes unproductive times during the operation. The limitations found when using a cause and effect diagram are: If the discussion is not 
controlled properly it may deviate from its objective and sometimes effort is wasted in identifying causes which have little effect on the problem.

\subsection{Analysis of Damages in Automatic Machines}

Figure 2 in an analysis horizon of 8 months identifies a total of 247 machine failures, with 123 mechanical failures, 86 direct human errors, 12 electronic, 10 neumatic and 16 various.

In the case of the first type of failure, $40 \%$ are the consequence of misuse, which is also due to labor; that is, a total of 135 failures.

It is concluded that $54.6 \%$ of stoppages are due to labor, so all the failures of this percentage are detailed: press foot virado (24\%), bad loading pallet (21\%), descentrated press foot and needle (19\%), swallowed wire hook (12\%), $\mathrm{z}$ motor discalibration ( $9 \%$ ), pin $\mathrm{x}$ desalinated $(6 \%)$, bad equipment operation (4\%), hook and bar discalibration $(2 \%)$, breaking pallet $(1 \%)$, sewing order misdirected $(1 \%)$, incorrect placement of the coil $(1 \%)$.

Most failures in automatic machines are due to the lack of staff training since they do not have basic maintenance knowledge. With this analysis it is detected that there are unproductive times in automatic machines and goal setting is done: increase the production standards by $5 \%$ in $40 \%$ of the models by TPM improvements, guarantee that the standards of all the models are adequate to avoid unproductive times, decrease the incidence of labor failures by $20 \%$.

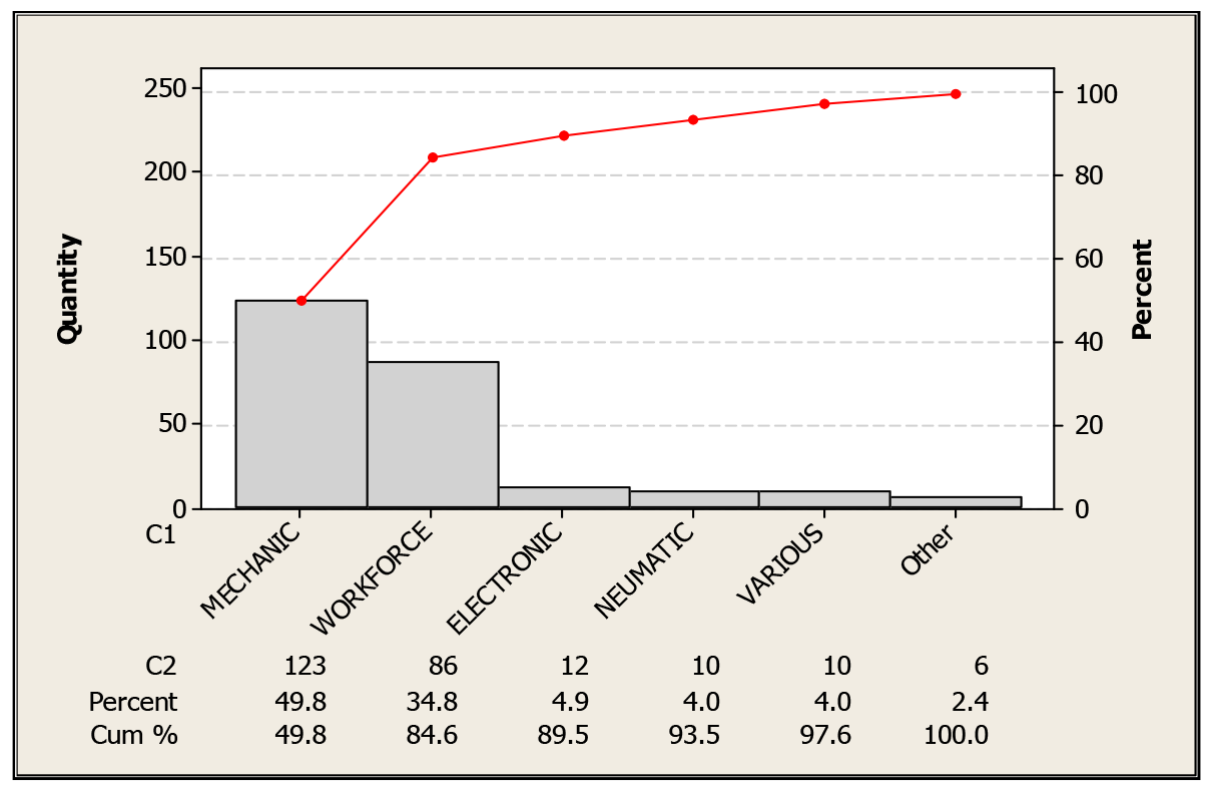

Figure 2. Faults in Automatic Machines, from Minitab 17

\subsection{Unscheduled Stoppages}

The project analyzes 13 automatic machines of the sewing process and checked the hours of unscheduled downtime during the 8-month study. Out of a total of 2560 available hours, there are 241 hours of unscheduled stoppages. These stoppages are those that interrupt the normal flow of production and in which it can not be produced. Figure 3 shows the hours for each of the machines and the maintenance costs presented in each machine. 


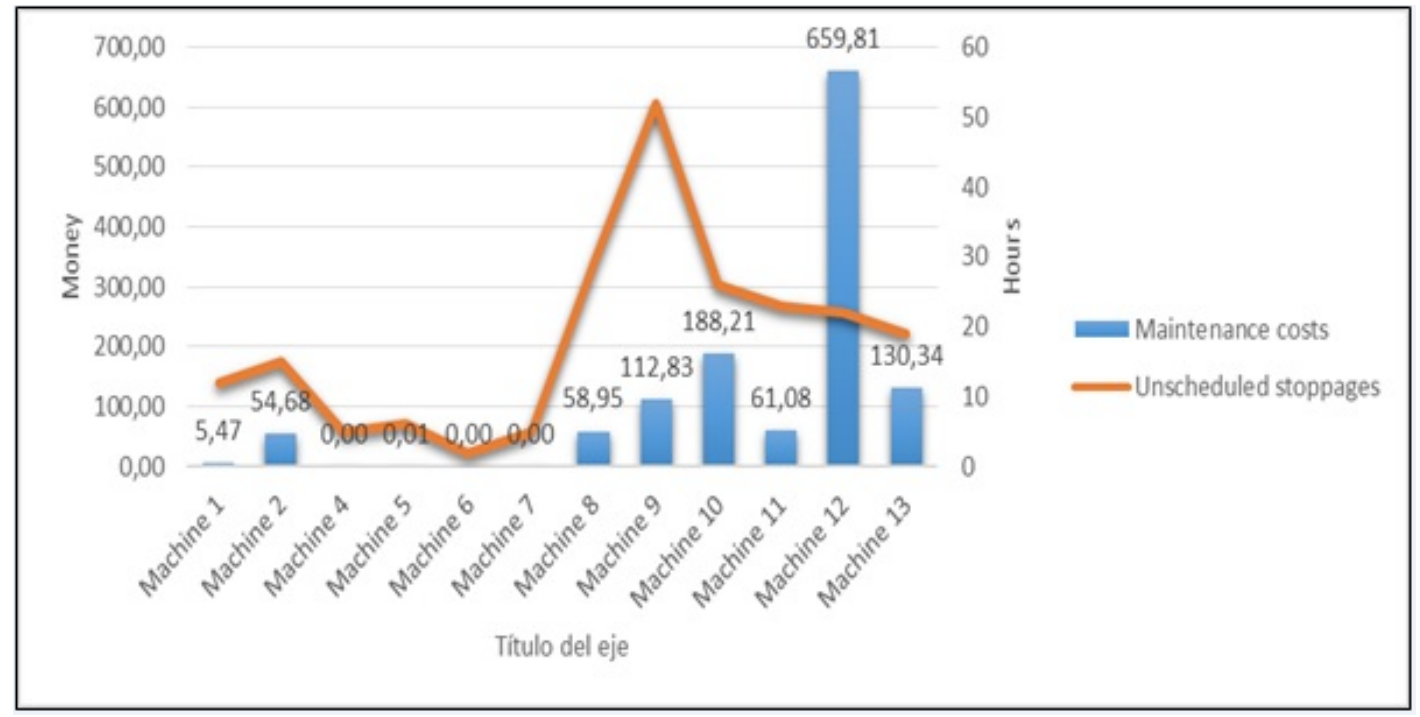

Figure 3. Unscheduled stoppages and maintenance costs

\subsection{Operator Training TPM}

The training machine is defined and workers are selected to become a TPM operator. The induction must be carried out with regard to the established policies, cleaning according to the work instructions and the 5 S's program that include initial cleaning, preventive measures cleaning, inspection standard, check list and organizing pallets of automatic machines, the method to help diagnose in which the operator becomes the alert voice when the machine presents some type of anomaly, basic maintenance, the revision of standards and impact of the TPM on productivity.

The standardization of TPM must be written in a controlled document and published in the company's management system, the training plan must be defined, the cleaning instruction must be created, and any changes that are pertinent in the operating instructions of the machines automatic are executed. All related persons should participate jointly, e.g. equipment planner (Planning Department), equipment user (Manufacturing Department), and maintenance person (Maintenance Department), etc (Shen, 2015).

\section{Discussion}

The implementation of TPM in sewing process allows the reduction of unproductive times since the operators are trained to execute basic arrangements in the machines, in addition they have the training in the best practices for the use during the operation. The direct result of this knowledge implies a greater use of time and the standards increase. Figure 4 shows how in some cases the percentage of improvement reaches even $8 \%$ and in other models of greater process to $3 \%$. The label ANN, INN, etc represents the model name.

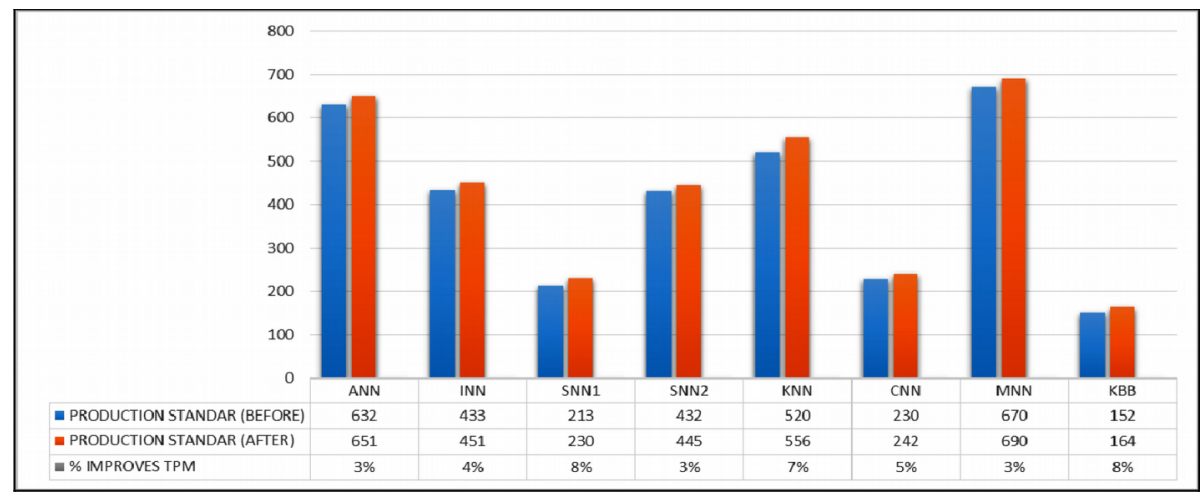

Figure 4. Improves TPM for standard production 
The research offers companies of the footwear industry the possibility of implementing TPM, through a structured and planned process that allows to reduce human errors. Figure 5 shows the variation in the number of human errors in the automatic machines. In June there are 18 failures and after TPM this number is 5 , resulting in a reduction of $72.2 \%$.

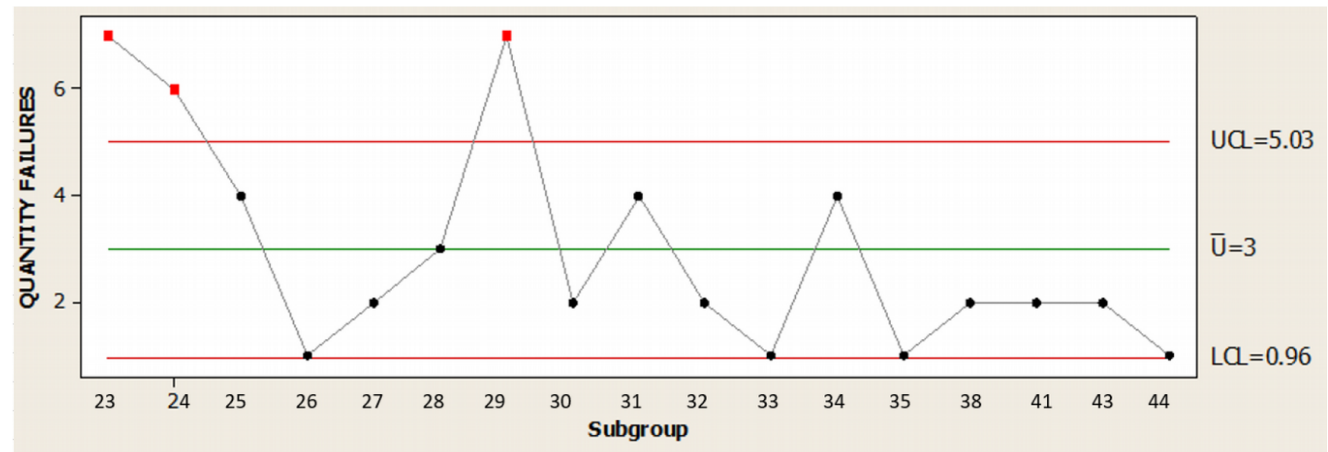

Figure 5. Number of human errors, from Minitab 17

\section{Conclusions}

The detailed analysis of the failures in critical machines positively influences the implementation of TPM in the four phases proposed by the project model: preparatory, introduction, implementation and consolidation. The structure of the model allows executing the activities so that the root cause detected as unproductive times due to human errors becomes an opportunity for improvement with high results at the end of the implementation, which makes the model a powerful tool for maintenance management.

Establishing a training program to turn the staff into TPM workers under the slogan "My machine my responsibility, I receive well, I deliver well" increases the production standards on average of 5\%; that is, from a standard production average of 410 pair/turn before TPM to a standard production average of 429 pair/turn after TPM i.e. 19 pairs per model.

Limitations of this paper must be mentioned. Firstly, we did not include all the causes of the problem in the analysis between automatic and manual sewing machines. By using cause effect diagram, maybe causes have been detected with very little effect on the availability of machines. Other limitation of this study is that TPM is implemented from the point of view of industrial processes and excludes services companies.

About potential for further research. There is an opportunity to investigate the relationship between the criticality analysis of machines and the application of preventive maintenance to increase the levels of availability of machinery.

\section{Acknowledgment}

The authors thank the National Footwear Chamber of Ecuador and the Technical University of Ambato for the support provided during the execution of this work within the framework of the research project called "Operational optimization based on a lean dynamic system of alert of failures in the production processes for the footwear industry".

\section{Declaration of Conflicting Interests}

The authors declared no potential conflicts of interest with respect to the research, authorship, and/or publication of this article.

\section{Funding}

The authors received no financial support for the research, authorship, and/or publication of this article. 


\section{References}

Álvarez, K., Aldas, D., \& Reyes, J. (2017). Towards Lean Manufacturing from Theory of Constraints: A Case Study in Footwear Industry. Industrial Engineering, Management Science and Application (ICIMSA). Seoul, South Korea. https://doi.org/10.1109/ICIMSA.2017.7985615

García, J., Romero, J., \& Noriega, S. (2012). Administrative factors related to the success of total productive maintenance. Accountancy. Administration, 57(4).

Hernández, A., Escobar, C., Larios, J., \& Noriega, S. (2015). Critical success factors for the strategic deployment of total. Contaduría y Administración, 60, 82-106.

Marín, J., \& Martínez, R. (2013). Barriers and facilitators of the TPM implementation. Intangible Capital, 9(3).

Marulanda, N., \& González, H. (2017). Objetivos y decisiones estratégicas operacionales; Objectives and strategic operational decisions to support lean manufacturing. Suma de Negocios, 8(18).

https://doi.org/10.1016/j.sumneg.2017.11.005

Matos, R. (2012). Development of a Total Productive Maintenance (TPM) Program in the Special mixture's area of a Miller. Faculty of Engineering Industry. "Engineering Magazine", 19(3), 66.

Pacheco, J., Carbajal, E., \& Stoll, C. (2017). Continuous Flow in Labour-Intensive Manufacturing Process. The 4th International Conference on Manufacturing and Industrial Technologies. Portugal. https://doi.org/10.1088/1757899X/212/1/012019

Pearce, A., \& Pons, D. (2013). Implementing lean practices: managing the transformation risks. Journal of industrial engineering, 790291, 19. https://doi.org/10.1155/2013/790291

Reyes, J., Aldas, D., Salazar, E., Armendáriz, E., Álvarez, K., Nuñez, J. et al. (2017). Finite Progressive Planning for the Assembly Process in. The 4th International Conference on Manufacturing and Industrial Technologies. Portugal. https://doi.org/10.1088/1757-899X/212/1/012020

Soliman, M., Saurin, T., \& Anzanello, M. (2018). The impacts of lean production on the complexity of socio-techincal systems. International Journal of Production Economics. Brazil. https://doi.org/10.1016/j.ijpe.2018.01.024

Shen, C. (2015). Discussion on key successful factors of TPM in enterprises. Journal of Applied Research and Technology, 13(3). https://doi.org/10.1016/j.jart.2015.05.002

Suzuki, T. (1994). TPM In Process Industries. Editorial Taylor \& Francis Group.

Villegas, L., \& Velez, A. (2014). Implantation of Total Productive Maintenance-TPM-scenarios of corporative fusion. 12th Latin American and Caribbean Conference for Engineering and Tecbnology. "Excellence in Engineering to Enhance a Country's Productivity”. Guayaquil, Ecuador.

Journal of Industrial Engineering and Management, 2018 (www.jiem.org)

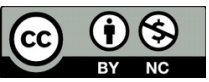

Article's contents are provided on an Attribution-Non Commercial 4.0 Creative commons International License. Readers are allowed to copy, distribute and communicate article's contents, provided the author's and Journal of Industrial Engineering and Management's names are included. It must not be used for commercial purposes. To see the complete license contents, please visit https://creativecommons.org/licenses/by-nc/4.0/. 